\title{
Comparison of Three Commercially Available Amplification Assays, AMP CT, LCx, and COBAS AMPLICOR, for Detection of Chlamydia trachomatis in First-Void Urine
}

\author{
WIL H. F. GOESSENS, * JOHAN W. MOUTON, WILLEM I. VAN DER MEIJDEN, SABINE DEELEN \\ TINEKE H. VAN RIJSOORT-VOS, NICOLE LEMMENS-DEN TOOM, HENRI A. VERBRUGH, \\ AND ROEL P. VERKOOYEN \\ Department of Medical Microbiology and Infectious Diseases and Department of Dermato-Venereology, \\ University Hospital Rotterdam, Rotterdam, The Netherlands
}

Received 6 May 1997/Returned for modification 24 June 1997/Accepted 28 July 1997

\begin{abstract}
We compared the Gen-Probe transcription-mediated amplification assay (AMP CT), the Abbott LCx assay, and the Roche COBAS AMPLICOR assay for the detection of Chlamydia trachomatis in a mixed population in urine samples. First-void urine, urethral specimens, and cervical specimens in females were obtained from 1,000 patients (544 males and 456 females) visiting the outpatient sexually transmitted disease clinic of our hospital. The prevalence of $C$. trachomatis infection was $7.7 \%$ as determined by tissue culture of urethral and cervical specimens. The sensitivities of LCx, COBAS AMPLICOR, and AMP CT compared to cell culture were 79, 86, and $78 \%$, respectively. Sensitivity and specificity were recalculated by using a new "gold standard", i.e., a sample was considered to be true positive if two or more techniques yielded positive results. Specimens positive only by cell culture or positive in only one commercial amplification technique were retested by a previously described in-house PCR. After discordance analysis the sensitivities of LCx, COBAS AMPLICOR, and AMP CT were 84, 93, and $85 \%$, respectively. Specificity exceeded $99 \%$ for all three assays. With each method the sensitivity was lower for urine samples from females compared to urine samples from males. By application of this new gold standard, existing differences between methods are highlighted; future evaluations of new techniques should be validated against two or more amplification assays.
\end{abstract}

Chlamydia trachomatis is now the most common cause of sexually transmitted diseases (4). Among other serious complications, it frequently leads to infertility in women (8). Effective control of chlamydial urogenital infections has been hampered by the lack of rapid, effective, and easy methods of diagnosis. Isolation of $C$. trachomatis in cell culture has been considered the reference method for diagnosing chlamydia for many years $(1,29)$. The introduction of assays based on amplification of genetic material has subsequently increased the sensitivity of detecting chlamydial infections. These amplification techniques have first been compared to cell culture of urethral and cervical patient specimens $(19,27)$.

Because of the increased sensitivity of these nucleic acid amplification techniques, they recently have made possible the use of urine specimens for the detection of $C$. trachomatis in both men and women, thereby eliminating cumbersome sampling $(3,5,9,14,25)$. In addition, amplification assays are now available in automated formats, standardizing performance in clinical microbiology laboratories. These automated techniques, i.e., COBAS AMPLICOR and AMP CT, are not available yet in the United States since they are still waiting for Food and Drug Administration approval. These techniques, however, have already been introduced on the European market and, therefore, we were able to study the COBAS AMPLICOR PCR $(12,15)$ from Roche Diagnostic Systems (Basel, Switzerland), the transcription-mediated amplification assay AMP CT from Gen-Probe Inc. (San Diego, Calif.), and LCx of

\footnotetext{
* Corresponding author. Mailing address: Department of Medical Microbiology and Infectious Diseases, University Hospital Rotterdam, Dr. Molewaterplein 40, 3015 GD Rotterdam, The Netherlands. Phone: 31(0)10-4633531. Fax: +31(0)10-4633875. E-mail: Goessens@bacl.azr .nl.
}

Abbott Laboratories (Chicago, Ill.) for the detection of $C$. trachomatis in first-void urine and compare the results with those of tissue culture of cervical and/or urethral specimens.

\section{MATERIALS AND METHODS}

Patient population and specimen handling. Specimens were collected from 544 men and 456 women visiting the outpatient department of sexually transmitted diseases (STD) at the University Hospital of Rotterdam, The Netherlands, from February 1996 to July 1996. To determine sample-to-sample variation due to order of collection, the samples were collected in a block design of 250 samples each in the following order for females: block 1, cervical swab (CS), urethral swab (US), first-void urine (FVU); block 2, FVU, CS, US; block 3, CS, US, FVU; block 4, FVU, CS, US for females. For males the order of collection was US, FVU over all blocks. The chlamydial culture samples were collected with ENT Dacron swabs (Medical Wire, Corsham, United Kingdom), placed in $0.2 \mathrm{M}$ sucrose phosphate buffer, and stored at $4^{\circ} \mathrm{C}$ or, when not tested within $24 \mathrm{~h}$ after collection, at $-70^{\circ} \mathrm{C}$. The volume of urine collected was 40 to $50 \mathrm{ml}$. Urine specimens were stored and processed according to the instructions of the manufacturer.

Cell culture. Chlamydial culture was performed on cycloheximide-treated McCoy cells in microtiter plates and has been described extensively $(16,17,30)$. Briefly, two wells per plate were each inoculated with $0.2 \mathrm{ml}$ of a patient sample. After centrifugation for $60 \mathrm{~min}$ at $1,400 \times g$, the supernatant was replaced with $0.1 \mathrm{ml}$ of complete growth medium (Eagle minimal essential medium with Glutamax; Flow Laboratories Inc., Paisley, Scotland) containing $10 \%$ fetal calf serum (Flow), $1 \%$ vitamins (Flow), and $20 \mathrm{mg}$ of gentamicin, $5 \mathrm{mg}$ of amphotericin $\mathrm{B}, 25 \mathrm{mg}$ of vancomycin, $4.5 \mathrm{~g}$ of glucose, and $1 \mathrm{mg}$ of cycloheximide (Sigma Chemical Co., St. Louis, Mo.) ( $\mathrm{pH} 7.5)$ per liter. The plates were incubated at $37^{\circ} \mathrm{C}$ at $5 \% \mathrm{CO}_{2}$ for $48 \mathrm{~h}$. Thereafter, the monolayers were fixed with ethanol $(96 \%)$ for $10 \mathrm{~min}$ and stained with a fluorescent monoclonal antibody (Microtrak; Syva Co., Palo Alto, Calif.) specific for C. trachomatis and examined for inclusions. Culture results (two wells) were scored as follows: negative, no inclusions; $1^{+}, 1$ to 5 inclusions; $2^{+}, 6$ to 20 inclusions; $3^{+},>20$ inclusions.

AMP CT. The AMP CT procedure was carried out according to the instructions of the manufacturer. Briefly, the urine samples were incubated for $10 \mathrm{~min}$ at $37^{\circ} \mathrm{C}$ followed by centrifugation of $1.5 \mathrm{ml}$ of the specimen at $8,000 \times g$ for 5 min. The supernatant was decanted, and the pellet was resuspended in $200 \mu \mathrm{l}$ of specimen diluent buffer. Twenty-five microliters of amplification reagent was added to the propylene reaction tubes. After $200 \mu$ l of oil reagent was added to the reaction tube, $50 \mu \mathrm{l}$ of processed specimen was pipetted under the oil 
reagent. The tubes were incubated for $10 \mathrm{~min}$ at $95^{\circ} \mathrm{C}$ in a heating block (Diagnostic Grifols S.A., Barcelona, Spain). After cooling down in a heating block at $42^{\circ} \mathrm{C}$ for $5 \mathrm{~min}, 25 \mu \mathrm{l}$ of enzyme reagent was added. After incubation for $1 \mathrm{~h}$ at $42^{\circ} \mathrm{C}, 20 \mu \mathrm{l}$ of termination reagent was added, and the mixture was incubated again for $10 \mathrm{~min}$ at $42^{\circ} \mathrm{C}$. After addition of $100 \mu \mathrm{l}$ of probe reagent, the tubes were briefly vortexed and incubated for $15 \mathrm{~min}$ at $60^{\circ} \mathrm{C}$ in a water bath. After 300 $\mu \mathrm{l}$ of selection reagent was added, the tubes were incubated for $10 \mathrm{~min}$ at $60^{\circ} \mathrm{C}$ in the water bath and cooled down for $10 \mathrm{~min}$ at room temperature. The hybridization protection assay with acridinium-ester-labeled DNA probes specific for the target organism was used for detection. Positive and negative controls were included in every run. All pipetting was done by using aerosol-resistant tips.

LCx. For LCx, $1 \mathrm{ml}$ of FVU was pipetted in a 1.7-ml microcentrifuge tube, and the tube was centrifuged at $15,000 \times g$ for $15 \mathrm{~min}$ (Eppendorf centrifuge $5415 \mathrm{C}$; Netheler Hinz, GmbH, Hamburg, Germany). The supernatant was replaced with $1 \mathrm{ml}$ of urine resuspension buffer (provided with the LCx kit), and the tubes were placed in a heating block $\left(95\right.$ to $100^{\circ} \mathrm{C}$ ) for $15 \mathrm{~min}$. After cooling to room temperature, the samples were tested immediately by $\mathrm{LCx}$ or were stored at $-20^{\circ} \mathrm{C}$ for future testing.

The LCx assay was performed and evaluated according to manufacturer's instructions. Briefly, $100 \mu \mathrm{l}$ of the processed urine was transferred to individual LCx unit-dose tubes containing $100 \mu \mathrm{l}$ of the LCx mixture (four oligonucleotides specific for the C. trachomatis plasmid, DNA ligase, polymerase, $\mathrm{NAD}^{+}, \mathrm{Mg}^{2+}$, dCTP, and dTTP in a pH 7.8 buffer). Two positive and negative controls as well as two calibrators were assayed with each batch of samples. The samples were processed in a thermocycler (model 480; Perkin-Elmer Cetus, Norwalk, Conn.) for 40 cycles of $1 \mathrm{~s}$ at $97^{\circ} \mathrm{C}, 1 \mathrm{~s}$ at $55^{\circ} \mathrm{C}$, and $50 \mathrm{~s}$ at $62^{\circ} \mathrm{C}$. The controls, calibrators, and samples were then centrifuged at $8,000 \times g$ for $1 \mathrm{~s}$ and were transferred to the LCx reaction cells. Amplification products were qualitatively detected in an LCX analyzer.

COBAS AMPLICOR PCR. The COBAS AMPLICOR test was performed according to the manufacturer's instructions. In brief, $0.5 \mathrm{ml}$ of wash buffer was added to a $1.5-\mathrm{ml}$ reaction tube. Subsequently, $0.5 \mathrm{ml}$ of well-mixed urine was added to the tube containing the wash buffer. This mix was incubated for $15 \mathrm{~min}$ at $37^{\circ} \mathrm{C}$, followed by centrifugation at $14,000 \times g$ for $5 \mathrm{~min}$ at room temperature. The supernatant was discarded, and the pellet was resuspended with $0.25 \mathrm{ml}$ of lysis buffer, vortexed, and incubated for $15 \mathrm{~min}$ at room temperature. An equal volume $(0.25 \mathrm{ml})$ of specimen diluent buffer (Roche Diagnostic Systems) was added immediately after incubation. The tubes were vortexed thoroughly and centrifuged at $14,000 \times g$ for $10 \mathrm{~min}$. Fifty microliters of the supernatant was transferred to amplification tubes.

COBAS AMPLICOR $C$. trachomatis is performed in a multiplex format including $C$. trachomatis, Neisseria gonorrhoeae, and an internal control. The internal control of amplification in the COBAS AMPLICOR assay is a sequence of plasmid DNA with primer-binding regions identical to those of the $C$. trachomatis target sequence and a randomized internal sequence with a length and base composition similar to those of the $C$. trachomatis target sequence. A unique probe-binding region differentiates the internal control from the target amplicon. The internal control is introduced into each amplification reaction and is coamplified with the possible target DNA from the clinical specimen.

The amplified nucleotide sequences for the internal control and C. trachomatis were automatically detected by using target-specific DNA probes coated on magnetic particles. The $A_{660}$ s were measured by the built-in spectrophotometer. All pipetting was performed with micropipettes with aerosol barrier tips.

In-house PCR. (i) Urine. The urine samples were thawed at room temperature and vortexed, and $1.5 \mathrm{ml}$ was transferred to a clean tube and incubated for $15 \mathrm{~min}$ at $37^{\circ} \mathrm{C}$. The specimens were then centrifuged for $30 \mathrm{~min}$ at $14,000 \times g$ at $37^{\circ} \mathrm{C}$. The supernatant was removed, and the pellet was treated with $80 \mu$ l of lysis buffer (50 mM Tris-HCl [pH 7.5], $1 \%$ Triton X-100, $1 \mathrm{mM}$ EDTA, and $250 \mu \mathrm{g}$ of proteinase $\mathrm{K}$ per $\mathrm{ml}$ ). After incubation at $37^{\circ} \mathrm{C}$ for $1 \mathrm{~h}$ the DNA in the lysates was extracted and purified with $4 \mathrm{M}$ guanidine-isothiocyanate and Celite according to the method of Boom et al. (6). At the final step the DNA was eluted in $100 \mu \mathrm{l}$ of $10 \mathrm{mM}$ Tris- $\mathrm{HCl}(\mathrm{pH} 8.0)$.

(ii) Cervical and urethral swabs. Specimens for PCR analysis were treated as described before (13). Briefly, a 400- $\mu$ l sample was centrifuged for $30 \mathrm{~min}$ at $14,000 \times g$, and the pellet was treated with $40 \mu \mathrm{l}$ of lysis buffer. After incubation at $37^{\circ} \mathrm{C}$ for $1 \mathrm{~h}$, the lysates were boiled for $10 \mathrm{~min}$ and centrifuged briefly. From each lysate, $8 \mu \mathrm{l}$ was added to $92 \mu \mathrm{l}$ of the PCR mixture.

(iii) Primers and PCR protocol. PCR was performed in a $100-\mu l$ volume under standard conditions with $8 \mu \mathrm{l}$ of the DNA sample. Primers recognizing sequences of the endogenous plasmid of $C$. trachomatis were used: T1, GGACAAATCGT ATCTCGG; T2, GAAACCAACTCTACGCTG. PCR was performed in $100 \mu \mathrm{l}$ of the PCR solution, containing $50 \mathrm{mM} \mathrm{KCl}, 10 \mathrm{mM}$ Tris- $\mathrm{HCl}(\mathrm{pH} 8.3), 2.5 \mathrm{mM}$ $\mathrm{MgCl}_{2}, 200 \mu \mathrm{M}$ each deoxynucleoside triphosphate, $50 \mathrm{pmol}$ of each primer, 0.1 mg of gelatin per ml, 0.2 U of Taq DNA polymerase (Sphaero-Q, Leiden, The Netherlands), and $8 \mu$ lof the sample. The reaction mixture was overlaid with 100 $\mu \mathrm{l}$ of mineral oil (Sigma) to prevent evaporation and was preincubated for $5 \mathrm{~min}$ at $94^{\circ} \mathrm{C}$ for DNA denaturation. Forty cycles of amplification were performed with a PCR processor (Biomed GmbH, Theres, Germany). Each cycle consisted of a denaturation step at $94^{\circ} \mathrm{C}$ for $1 \mathrm{~min}$, a primer-annealing step at $55^{\circ} \mathrm{C}$ for 1 min, and a chain elongation step at $74^{\circ} \mathrm{C}$ for $2 \mathrm{~min}$. After 40 cycles, a temperature delay step of $5 \mathrm{~min}$ at $74^{\circ} \mathrm{C}$ completed elongation. A $40-\mu \mathrm{l}$ volume of the amplified PCR product was analyzed by agarose $(1.5 \%$, wt/vol) gel electrophoresis.

(iv) Southern blot analysis of PCR products. DNA was transferred from agarose to Hybond-plus nylon filters (Amersham International, Amersham, United Kingdom) by electrophoretic transfer. The PCR products were analyzed with a $C$. trachomatis-specific probe (CGCAGCGCTAGAGGCCGGTCTATT TATGAT).

Analysis of results. Discordant analysis was based on a classical comparison of cell culture and, for example, LCx. The in-house PCR was performed first on FVU; if this result was negative, the in-house PCR was performed on the US and/or CS samples. A cell culture-negative and LCX-positive result was considered to be confirmed positive if the in-house PCR on FVU was positive. If the in-house PCR was negative, the LCx result was considered to be false positive. A culture-positive positive and LCx-negative result was considered to be false negative if the FVU was positive by the in-house PCR. If the FVU by the in-house PCR was negative and the US and/or CS specimen was positive by the in-house PCR, the LCx was considered false negative due to sample-to-sample variation. If the FVU, US, and CS (if applicable) remained negative by the in-house PCR, DNA was isolated from the inoculated cell culture monolayers and subjected to PCR. The cell culture result was considered true positive if the inoculated monolayer was confirmed by the in-house PCR of the scraped monolayer. Similar discordant analyses were performed for cell culture versus AMP $\mathrm{CT}$ and cell culture versus COBAS AMPLICOR. In an alternative discrepancy analysis, true-positive patients were identified. A result was considered true positive if two or more diagnostic assays were positive. All discrepant results were confirmed by using the in-house PCR, which was performed on the FVU, US, and CS samples, if applicable. If the in-house PCR did not confirm the positive result, the result was considered false positive. If a cell culture-positive result could not be confirmed by any of the three commercial amplification techniques or by the in-house PCR of the FVU, CS, and US samples, DNA was isolated from the inoculated cell culture monolayers and subjected to the inhouse PCR. The cell culture result of the discrepant specimen was considered true positive if the in-house PCR of the scraped monolayer was positive.

Statistics. All demographic data and laboratory results were coded, entered into a database, and subjected to standard verification procedures. The data were analyzed by using SPSS for Windows 95, version 7.0. Statistical evaluation of the collected data was performed by using Fisher's exact test. Probability values were two-tailed.

\section{RESULTS}

FVU, US, and, for females, CS specimens from 1,000 patients visiting the outpatient STD clinic were obtained. Cell cultures of US and CS specimens were positive for 37 male and 40 female patients, resulting in a prevalence of 6.8 and $8.8 \%$, respectively. Of these 77 culture-positive patients 61,60 , and 66 were detected by LCx, AMP CT, and COBAS AMPLICOR, respectively. Seventy-one of 77 cell-culture-positive samples were also positive in at least one of the three amplification techniques and were thus considered true positives. All three commercial techniques detected many additional positives. For the additional positives a discordant analysis was performed to rule out false positivity. Discordant analysis was performed by using the in-house PCR on FVU specimens. This resulted in 97 LCX-, 98 AMP CT-, and 106 COBAS AMPLICOR-positive samples.

The six urine specimens obtained from patients who were culture positive but negative in all three amplification assays were analyzed separately by performing a DNA extraction procedure on the monolayers of these samples followed by PCR. None of the six yielded a positive PCR signal, and the cell culture results were, therefore, considered false positive. Thus, 71 true cell culture-positive specimens remained.

Specimens negative by cell culture but positive by an amplification assay and confirmed by the in-house PCR on FVU were regarded as confirmed positives, resulting in $36 \mathrm{LCx}, 38$ AMP CT, and 40 COBAS AMPLICOR confirmed positives. For calculating the sensitivities and specificities of the three assays after this discrepancy analysis, a new "gold standard" was defined as confirmed cell culture positives also confirmed by each of the amplification techniques. This resulted in sensitivities for the LCx, AMP CT, and COBAS AMPLICOR of 90.7, 89.9, and $95.5 \%$, respectively (Fig. 1). 
SEPARATE ANALYSIS OF:

\begin{tabular}{|c|c|c|c|c|c|c|c|c|}
\hline \multicolumn{3}{|c|}{$\begin{array}{l}\text { LCx } \\
\text { and Cell Culture }\end{array}$} & \multicolumn{3}{|c|}{$\begin{array}{l}\text { AMP CT } \\
\text { and Cell Culture }\end{array}$} & \multicolumn{3}{|c|}{$\begin{array}{l}\text { COBAS AMPLICOR } \\
\text { and Cell Culture }\end{array}$} \\
\hline & \multicolumn{2}{|c|}{ Cell Culture } & \multicolumn{3}{|c|}{ Cell Culture } & \multicolumn{3}{|c|}{ Cell Culture } \\
\hline & + & - & & + & - & & + & - \\
\hline \multirow{2}{*}{$\stackrel{+}{L_{C x}}$} & 61 & 43 & + & 60 & 53 & + & 66 & 53 \\
\hline & 16 & 880 & - & 17 & 870 & & 11 & 870 \\
\hline
\end{tabular}

DISCORDANT RESULTS WERE RETESTED USING THE IN-HOUSE PCR

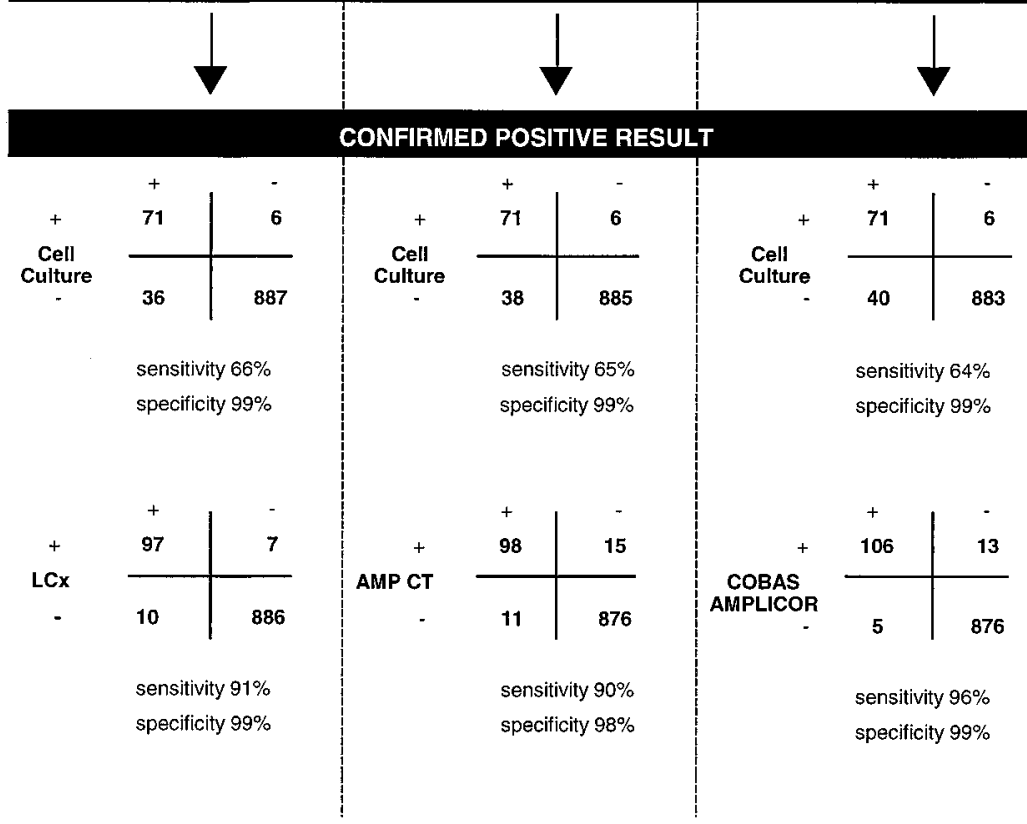

FIG. 1. Cell culture results versus the results of the amplification assays and results of discordant analysis of additional positives by in-house PCR on FVU.

The remaining 7 LCx-, 15 AMP CT-, and 13 COBAS AMPLICOR-positive samples that were negative by the in-house PCR on FVU were analyzed further by performing the inhouse PCR on the CS or US samples of the same patients. For the three assays, four, six, and six samples, respectively, could, thus, be confirmed and were regarded as true-positive samples. This finally resulted in $40 \mathrm{LCx}, 44$ AMP CT, and 46 COBAS AMPLICOR additional positives, respectively, for $101 \mathrm{LCx}-$, 104 AMP CT-, and 112 COBAS AMPLICOR-positive samples. The total numbers of positives increased to 111, 115, and 117 for LCx, AMP CT, and COBAS AMPLICOR, respectively. These additional positives resulted in small increases of the earlier-calculated sensitivities of the three commercial assays to $91,90.4$, and $95.7 \%$, respectively, and small increases in specificity.

Alternative discrepant analysis. The aforementioned discrepant analysis was performed to define a specimen as confirmed positive, for each technique separately. Another line of reasoning which we followed was to identify truly $C$. trachomatis-infected patients.

Since in this prospectively controlled study the three techniques were evaluated by using one and the same urine specimen, we do not have to take into account sample-to-sample variation due to the order of specimen collection. Therefore, we introduced a new gold standard, i.e., truly $C$. trachomatis- infected patients. Specimens not confirmed by one of the commercial assays were analyzed by using the in-house PCR on FVU, CS, or US specimens. By the LCx technique, initially 43 patients were determined to be positive. Of these 43,41 were confirmed by another commercial technique and one was confirmed by the in-house PCR. One specimen could not be confirmed and was considered false positive. Results for the other two techniques are given in Table 1.

By using this new gold standard, a total of 123 patients ( 71 culture-positive plus 52 confirmed) were considered truly in-

TABLE 1. Number of positives detected by each technique exclusively and confirmed by a commercial assay or by in-house PCR

\begin{tabular}{lccccc}
\hline & \multicolumn{5}{c}{ No. of patients confirmed } \\
\cline { 2 - 6 } \multicolumn{1}{c}{$\begin{array}{c}\text { Assay } \\
\text { (no. of positives) }\end{array}$} & $\begin{array}{c}\text { AMP CT } \\
\text { or COBAS }\end{array}$ & $\begin{array}{c}\text { LCx or } \\
\text { COBAS }\end{array}$ & $\begin{array}{c}\text { LCx } \\
\text { or }\end{array}$ & $\begin{array}{c}\text { In- } \\
\text { house }\end{array}$ & Total \\
& AMPICOR AMPLICOR & AMP & PCR $^{a}$ & \\
\hline LCx (43) & 41 & 42 & & 1 & 42 \\
AMP CT (53) & & 42 & & 3 & 45 \\
COBAS AMPLICOR (53) & & & 47 & 1 & 48 \\
\hline
\end{tabular}

${ }^{a} \mathrm{FVU}, \mathrm{CS}$, or US 
TABLE 2. Detection of true C. trachomatis infections ${ }^{a}$ by cell culture and amplification assays

\begin{tabular}{|c|c|c|c|c|}
\hline \multirow[b]{2}{*}{ Method } & \multicolumn{2}{|c|}{ No. of patients positive $(\%)^{b}$} & \multirow{2}{*}{$\begin{array}{l}\% \text { Sensitivity } \\
\left(\mathrm{CI}_{95}\right)^{c}\end{array}$} & \multirow{2}{*}{$\begin{array}{c}\% \\
\text { Specificity }\end{array}$} \\
\hline & $\begin{array}{l}\text { Females } \\
(n=57)\end{array}$ & $\begin{array}{c}\text { Males } \\
(n=66)\end{array}$ & & \\
\hline Cell culture & $37(64.9)$ & $34(51.5)$ & $57.7(48.4-66.6)$ & 99.3 \\
\hline $\mathrm{LCx}$ & $45(78.9)$ & $58(87.9)$ & $83.7(75.9-89.9)$ & 99.9 \\
\hline AMP CT & $44(77.2)$ & $61(92.4)$ & $85.4(77.8-91.1)$ & 99.1 \\
\hline COBAS AMPLICOR & $50(87.7)$ & $64(97)$ & $92.7(86.6-96.6)$ & 99.4 \\
\hline
\end{tabular}

${ }^{a}$ Truly infected patients $(n=123)$ are defined as patients whose urine specimens tested positive by two or more techniques or whose CS or US specimens were confirmed by the in-house PCR.

${ }^{b}$ No statistical significance was obtained for COBAS AMPLICOR versus LCx or AMP CT after analysis of the female or male results separately.

${ }^{c}$ Statistical significance was obtained for COBAS AMPLICOR versus LCx $(P=0.047)$. No statistical significance was obtained for COBAS AMPLICOR versus AMP $\mathrm{CT}(P=0.101)$. $\mathrm{CI}_{95}, 95 \%$ confidence interval.

fected by $C$. trachomatis (prevalence of $12.3 \%$ ). With these new findings, sensitivity and specificity were recalculated by using the above-mentioned definition (Table 2). The revised sensitivities of LCx, AMP CT, and COBAS AMPLICOR were 84,85 , and $93 \%$, respectively. Specificity exceeded $99 \%$ for all amplification techniques.

With this new gold standard the sensitivity of tissue culture was only $58 \%$, significantly lower than the sensitivities of the amplification methods. Furthermore, it can be seen that with all three amplification techniques the sensitivity for detecting a C. trachomatis infection in urine specimens is lower for females than for males.

\section{DISCUSSION}

Most papers describing an evaluation of a commercial amplification technique, i.e., PCR, LCx, or AMP CT, with urine specimens report sensitivities of 92 to $99 \%$ and excellent specificities $(3,5,9,14,24)$. So far, no direct comparison of the three automated amplification methods has been published. In the present study we were able to evaluate COBAS AMPLICOR versus LCX and AMP CT on one and the same specimen. The results of LCx, AMP CT, and COBAS AMPLICOR were analyzed separately versus cell culture, in order to calculate the sensitivity and specificity as if they were evaluated in a separate study. With this method, no statistically significant differences were demonstrated between the three commercially available amplification techniques (sensitivities of 91.0, 90.4, and 95.7\%, respectively)

In addition, we introduced a new gold standard, i.e., the ability of a test to identify truly infected patients. With this new gold standard sensitivity was $83.7 \%$ for LCx, $85.4 \%$ for AMP CT, and $92.7 \%$ for COBAS AMPLICOR; the difference in sensitivity between the COBAS AMPLICOR and LCX reached statistical significance $(P=0.047)$. No statistically significant difference $(P=0.101)$ between COBAS AMPLICOR and the AMP CT was found, although a similar trend was observed. These results are not in complete accordance with those reported by other authors regarding the sensitivities of the individual assays $(3,5,9,14,24)$. One should realize that the previously published data were obtained mainly in a male population, a fact that could be used as an argument to explain the differences demonstrated $(3,14)$. However, recently LCx and COBAS AMPLICOR have also been evaluated with samples from females with excellent sensitivity scores $(2,18,23)$. Even if the sensitivities of the assays are calculated solely for the male population, there is still a significant difference between the LCx (87.9\%), AMP CT (92.4\%), and COBAS AMPLICOR $(97 \%)$. The explanation for the differences between the present data and the previously reported data must be related to the reference method applied. This is best demonstrated by evaluating our own data. In a previous study (13) at our institute, a prevalence of $7.8 \%$ by tissue culture for $C$. trachomatis infection was reported. In that study an in-house PCR on US and CS specimens was evaluated. After discordant analysis a total of 110 true-positive patients were identified, giving rise to an actual prevalence of $9.9 \%$. With PCR, 102 of 110 were detected, giving a sensitivity of $92.7 \%$, whereas tissue culture had a sensitivity of $79.1 \%$ only.

In the present study prevalence by tissue culture was $7.1 \%$, indicating that no great shift has occurred in prevalence in this particular patient cohort. If COBAS AMPLICOR is regarded as the reference method, the sensitivity of tissue culture is $63.9 \%$ (71 of 111). Another example demonstrating the role of the reference method used was reported previously by our group. We analyzed AMP CT versus cell culture (21) by making use of the same specimens. The overall sensitivity for AMP CT was $92.4 \%$. In the present study the initial sensitivity for AMP CT was $89.9 \%$. The role of the reference method in the evaluation of the three assays is even more evident with the introduction of the new gold standard, i.e., truly infected patients. Truly infected patients are defined as those who are positive by two of the four assays used, i.e., three amplification assays and cell culture. By this measure the initially reported sensitivity of tissue culture further decreases to $57.7 \%$.

The differences between the sensitivities of the three amplification assays are not due to a difference in initial accuracy between the assays, since we diluted several $C$. trachomatispositive patient samples with a 10 -fold limiting dilution series and assayed these samples separately in the three amplification assays. No significant differences were observed between the three amplification assays (data not shown). Therefore, the differences have to be due to other factors. One of these factors could be overdilution of $C$. trachomatis by the urine volume collected. Abbott advises a maximum volume of $20 \mathrm{ml}$, and Roche advises a maximum volume of $50 \mathrm{ml}$. In this study we collected volumes of 40 to $50 \mathrm{ml}$. On the other hand, an excess in volume collected could also be beneficial in the sense that inhibitors are also diluted, influencing the sensitivity in a positive way. Another, more technical complication could be related to the volume added into the amplification assay. The initial volumes of the urine specimens used for amplification in AMP CT, LCx, and COBAS AMPLICOR are 1.5, 1, and 0.5 $\mathrm{ml}$, respectively. Of these specimen volumes, 375,100 , and 50 $\mu \mathrm{l}$, respectively, are included in the amplification reaction. On the basis of this calculation, one would conclude that the LCx technique, despite using twice the amount of the volume used in COBAS AMPLICOR, produces fewer positives, possibly due to a less accurate amplification/detection procedure. Another explanation would be that the pretreatment procedure of 
LCx is insufficient for neutralizing inhibitory substances. Other studies in which LCx was evaluated also reported a strikingly high number of false-negative results, most likely due to the presence of LCx inhibitors in urine specimens $(26,31)$.

AMP CT, on the other hand, used $375 \mu$ l of the initial urine specimen in the amplification procedure. However, even with an initial specimen 3.75 and 7.5 times larger than those used for LCx and COBAS AMPLICOR, this technique was not able to detect all positive specimens. The enzymes used in this amplification assay, however, are obviously not that vulnerable to inhibitory substances. The problem with these amplification techniques is that they seem to suffer from unfavorable ratios of target DNA or RNA to aspecific DNA or RNA and to inhibitory substances present in the processed sample. Probably all three techniques have some of these shortcomings. It seems, however, that at the moment COBAS AMPLICOR suffers less from these shortcomings since Roche Diagnostic Systems has reduced the initial volume size of the urine specimen from 8 to $0.5 \mathrm{ml}$, thereby reducing the volume used in the PCR twofold. In earlier papers sensitivities of 62 and $82 \%$ were reported $(11,28)$; it was recommended that $8 \mathrm{ml}$ of urine be processed. The present results show that this reduction in volume has actually led to an increased sensitivity, which points to the presence of inhibitory substances in urine. In addition, Roche Diagnostics has also introduced an internal control in their diagnostic assay, thereby optimizing the detection rate of the assay. In the present study 26 patients $(2.6 \%)$ had results indicating inhibition of the PCR. Only one specimen remained inhibited after being heated at $95^{\circ} \mathrm{C}$ for $10 \mathrm{~min}$ (data not shown). Since the introduction of COBAS AMPLICOR in our laboratory, 59 inhibited samples were detected, of which 14 became positive for $C$. trachomatis after heat treatment, indicating the necessity of an internal standard (data not shown).

It has become evident that the sensitivity of cell culture does not meet the demands of a reference method for nucleic acid amplification techniques. Therefore, in the present study we used the summary data of three independent amplification techniques combined with cell culture as an expanded gold standard. By applying this strict reference, the existing differences between methods are highlighted. In future evaluations of amplification techniques it should be emphasized that new techniques should be validated against two or more other amplification assays in combination with cell culture.

Our data for the three techniques show a reduced sensitivity for detection of $C$. trachomatis infections in females. AMP CT and LCx demonstrated unacceptably low sensitivities for the female population and, therefore, cannot be recommended as reliable methods for the detection of $C$. trachomatis infection in females. The explanation for these findings probably has to do with the fact that the pathology of chlamydia infection is localized mainly in the cervix, with a relatively low percentage of cases involving also infection of the urethra $(7,20,22)$. However, Pasternak et al. (23) and Chernesky et al. (10) claimed that they detected more positives in urine specimens than in cervical specimens, indicating that the endocervix may actually not be infected in some of these patients. Preliminary analysis by PCR of swab specimens obtained in this study do confirm these findings (data not shown). Of the 42 female $C$. trachomatis FVU-positive patients, only 35 and 33 tested positive by CS and US, respectively. Of the 44 male $C$. trachomatis FVU-positive patients, 39 were positive by US. The previously reported results and our preliminary results, however, may be influenced by the presence of PCR and cell culture inhibitors in cervical materials. Thus, we feel that for the female population urine screening for $C$. trachomatis needs to be further improved or supplemented by swab specimens from the cervix, and there remains room for improvement of these recently introduced test systems.

\section{ACKNOWLEDGMENTS}

We thank Gen-Probe, Roche Diagnostic Systems, and Abbott for supplying reagents and equipment. We are also grateful to the doctors and nursing personnel of the STD department for collecting samples and relevant patient data.

\section{REFERENCES}

1. Barnes, R. C. 1989. Laboratory diagnosis of human chlamydial infections. Clin. Microbiol. Rev. 2:119-136.

2. Bassiri, M., H. Y. Hu, M. A. Domeika, J. Burczak, L.-O. Svensson, H. H. Lee, and P.-A. Mårdh. 1995. Detection of Chlamydia trachomatis in urine specimens from women by ligase chain reaction. J. Clin. Microbiol. 33:898-900.

3. Bauwens, J. E., A. M. Clark, M. J. Loeffelholz, S. A. Herman, and W. E. Stamm. 1993. Diagnosis of Chlamydia trachomatis urethritis in men by polymerase chain reaction assay of first-catch urine. J. Clin. Microbiol. 31:30133016.

4. Bell, T. A., and J. T. Grayston. 1986. CDC guidelines for prevention and control of Chlamydia trachomatis infections. Ann. Intern. Med. 104:524-526.

5. Bianchi, A., C. Scieux, N. Brunat, D. Vexiau, M. Kermanach, P. Pezin, M. Janier, P. Morel, and P. H. Lagrange. 1994. An evaluation of the polymerase chain reaction amplicor Chlamydia trachomatis in male urine and female urogenital specimens. Sex. Transm. Dis. 21:196-200.

6. Boom, R., C. J. Sol, M. M. Salimans, C. L. Jansen, P. M. Wertheim-van Dillen, and J. van der Noordaa. 1990. Rapid and simple method for purification of nucleic acids. J. Clin. Microbiol. 28:495-503.

7. Bradley, M. G., D. Hobson, N. Lee, I. A. Tait, and E. Rees. 1985. Chlamydial infections of the urethra in women. Genitourin. Med. 61:371-375.

8. Centers for Disease Control. 1985. Chlamydia trachomatis infections. Policy guidelines for prevention and control. Morbid. Mortal. Weekly Rep. 35:535574.

9. Chernesky, M. A., H. H. Lee, J. Schachter, J. D. Burczak, W. E. Stamm, W. M. McCormack, and T. C. Quinn. 1994. Diagnosis of Chlamydia trachomatis urethral infection in symptomatic and asymptomatic men by testing first-void urine in a ligase chain reaction assay. J. Infect. Dis. 170:1308-1311.

10. Chernesky, M. A., D. Jang, H. Lee, J. D. Burczak, H. Hu, J. Sellors, S. J. Tomazic-Allen, and J. B. Mahony. 1994. Diagnosis of Chlamydia trachomatis infections in men and women by testing first-void urine by ligase chain reaction. J. Clin. Microbiol. 32:2682-2685.

11. de Barbeyrac, B., P. Rodriguez, B. Dutilh, P. Le Roux, and C. Bebear. 1995. Detection of Chlamydia trachomatis by ligase chain reaction compared with polymerase chain reaction and cell culture in urogenital specimens. Genitourin. Med. 71:382-386.

12. DiDomenico, N., H. Link, R. Knobel, T. Caratsch, W. Weschler, Z. G. Loewy, and M. Rosenstraus. 1996. COBAS AMPLICOR ${ }^{\mathrm{TM}}$ : a fully automated RNA and DNA amplification and detection system for routine diagnostic PCR. Clin Chem. 42:1915-1923.

13. Goessens, W. H. F., J. A. J. W. Kluytmans, N. den Toom, T. H. van RijsoortVos, B. G. M. Niesters, E. Stolz, H. A. Verbrugh, and W. G. V. Quint. 1995. Influence of volume of sample processed on detection of Chlamydia trachomatis in urogenital samples by PCR. J. Clin. Microbiol. 33:251-253.

14. Jaschek, G., C. A. Gaydos, L. E. Welsh, and T. C. Quinn. 1993. Direct detection of Chlamydia trachomatis in urine specimens from symptomatic and asymptomatic men by using a rapid polymerase chain reaction assay. J. Clin. Microbiol. 31:1209-1212.

15. Jungkind, D., S. DiRenzo, K. G. Beavis, and N. S. Silverman. 1996. Evaluation of automated COBAS AMPLICOR PCR system for detection of several infectious agents and its impact on laboratory management. J. Clin. Microbiol. 34:2778-2783.

16. Kluytmans, J. A. J. W., H. G. M. Niesters, J. W. Mouton, W. G. V. Quint J. A. J. Ijpelaar, J. H. van Rijsoort-Vos, L. Habbema, E. Stolz, M. F. Miche and J. H. T. Wagenvoort. 1991. Performance of a nonisotopic DNA probe for detection of Chlamydia trachomatis in urogenital specimens. J. Clin. Microbiol. 29:2685-2689.

17. Kluytmans, J. A. J. W., W. H. F. Goessens, J. W. Mouton, J. H. van RijsoortVos, H. G. M. Niesters, W. G. V. Quint, L. Habbema, E. Stolz, and J. H. T. Wagenvoort. 1993. Evaluation of Clearview and Magic Lite tests, polymerase chain reaction, and cell culture for detection of Chlamydia trachomatis in urogenital specimens. J. Clin. Microbiol. 31:3204-3210.

18. Lee, H. H., M. A. Chernesky, J. Schachter, J. D. Burczak, W. W. Andrews, S. Muldoon, G. Leckie, and W. E. Stamm. 1995. Diagnosis of Chlamydia trachomatis genitourinary infection in women by ligase chain reaction of urine. Lancet 345:213-216.

19. Loeffelholz, M. J., C. A. Lewinski, S. R. Silver, A. P. Purohit, S. A. Herman, D. A. Buonagurio, and E. A. Dragon. 1992. Detection of Chlamydia trachomatis in endocervical specimens by polymerase chain reaction. J. Clin. Microbiol. 30:2847-2851.

20. Morris, R., J. Legault, and C. Baker. 1993. Prevalence of isolated urethra 
asymptomatic Chlamydia trachomatis infection in the absence of cervical infection in incarcerated adolescent girls. Sex. Transm. Dis. 20:198-200

21. Mouton, J. W., R. Verkooyen, W. I. van der Meijden, T. H. van Rijsoort-Vos, W. H. F. Goessens, J. A. J. W. Kluytmans, S. D. A. Deelen, A. Luijendijk and H. A. Verbrugh. 1997. Detection of Chlamydia trachomatis in male and female urine specimens by using the amplified Chlamydia trachomatis test. J. Clin. Microbiol. 35:1369-1372.

22. Paavonen, J., and E. Vesterinen. 1982. Chlamydia trachomatis in cervicitis and urethritis in women. Scand. J. Infect. Dis. 32:45-54.

23. Pasternack, R., P. Vuorinen, A. Kuukankorpi, T. Pitkäjärvi, and A. Miettinen. 1996. Detection of Chlamydia trachomatis infections in women by Amplicor PCR: comparison of diagnostic performance with urine and cervical specimens. J. Clin. Microbiol. 34:995-998.

24. Pasternack, R., P. Vuorinen, and A. Miettinen. 1997. Evaluation of the Gen-Probe Chlamydia trachomatis transcription-mediated amplification assay with urine specimens from women. J. Clin. Microbiol. 35:676-678.

25. Quinn, T. C., L. Welsh, A. Lentz, K. Crotchfelt, J. Zenilman, J. Newhall, and C. Gaydos. 1996. Diagnosis by AMPLICOR PCR of Chlamydia trachomatis infection in urine samples from women and men attending sexually transmitted disease clinics. J. Clin. Microbiol. 34:1401-1406.

26. Ridgway, G. L., G. Mumtaz, A. J. Robinson, M. Franchini, C. Carder, J.
Bruczak, and H. Lee. 1996. Comparison of the ligase chain reaction with cell culture for the diagnosis of Chlamydia trachomatis infection in women. J. Clin. Pathol. 49:116-119.

27. Schachter, J., W. E. Stamm, T. C. Quinn, W. W. Andrews, J. D. Burczak, and H. H. Lee. 1994. Ligase chain reaction to detect Chlamydia trachomatis infection of the cervix. J. Clin. Microbiol. 32:2540-2543.

28. Stary, A., S. Tomazic-Allen, B. Choueiri, J. Burczak, K. Steyrer, and H. Lee. 1996. Comparison of DNA amplification methods for the detection of Chlamydia trachomatis in first-void urine from asymptomatic military recruits. Sex. Transm. Dis. 23:97-102.

29. Taylor-Robinson, D. 1992. Laboratory methods for chlamydial infections. J. Infect. Dis. 25(Suppl. 1):61-67.

30. Thewessen, E. A. P. M., I. Freundt, J. H. van Rijsoort-Vos, E. Stolz, M. F. Michel, and J. H. T. Wagenvoort. 1989. Comparison of HeLa 229 and McCoy cell cultures for detection of Chlamydia trachomatis in clinical specimens. J. Clin. Microbiol. 27:1399-1400.

31. Van Doornum, G. J. J., M. Buimer, M. Prins, C. J. M. Henquet, R. A Coutinho, P. K. Plier, S. Tomazic-Allen, H. Hu, and H. Lee. 1995. Detection of Chlamydia trachomatis infection in urine samples from men and women by ligase chain reaction. J. Clin. Microbiol. 33:2042-2047. 